gleichen die Herkunft des Pilzzusatzes selbst. Seltsam genug bleibt die Verwendung gerade unseres Gasteromyceten, da derselbe weder eine Rolle unter den Speisepilzen spielt, noch bequem einzusammeln ist.

E. Michael") trennt den "ebbaren" Rhizopogon virens von dem ,ungenießbaren" Rhizopogon luteolus; andere Autoren vereinigen beide, so G. Winter ${ }^{2}$ ); J. Schroeter ${ }^{3}$ ), Ed. Fischer ${ }^{4}$ ).

Nach A. Rosenthal ${ }^{5}$ ) soll Rhizopogon luteolus (fälschlich anteolus genannt) ekelhaft schmecken und aphrodisische Kräfte besitzen. Vielleicht ist der schlechte Geschmack und Geruch überreifer Exemplare, die Winter als "mistartig stinkend" bezeichnet, der Grund für eine Trennung gewesen.

C. $\mathrm{Mez}^{6}$ ) erwähnt den Pilz bei Trüffeluntersuchungen und bildet seine Sporen n Fig. $213 \mathrm{~g}$ trefflich ab.

1) Nichael, Führer für Pilzfreunde 1905, 3, Nr. 128, 129.

2) Winter, Die Pilze Deutschlands, Österreichs und der Schweiz in Rabenborst, Kryptogamen-Flora $1884,1,880$.

$\left.{ }^{3}\right)$ Schroeter, Pilze in Cohn, Kryptogamen-Flora von Schlesien 1889, 1, 713.

4) Fischer in Engler und Prantl, Natürliche Pflanzenfamilien 1900, 1, 1**, 312.

5) Rosenthal, Heil-, Nutz- a. Giftpflanzen 1862, 1070; vergl. auch G. Dragendorff, Die Heilpflanzen 1898, 44.

5) Mez, Das Mikroskop 1904, 233.

\title{
Die Rhizome des Adlerfarnes (Pteris aquilina L.) als Stärke-Quelle.
}

\author{
Von \\ Dr. Ass. Zlataroff, \\ Vorstand der Industrie-Abteilung der Direlation für öffentliche Fürsorge \\ in Sofia (Bulgarien).
}

[Eingegangen am 1. April 1918.]

Die Beobachtung, dab das Wildschwein sorgsam nach den Winterrhizomen des Adlerfarnes als Nahrung sucht, brachte zwei Knaben auf den Gedanken, die Direktion für öffentliche Fürsorge auf diese Rhizome als eine Mehlquelle aufmerksam zu machen.

Die Nachforschungen, die ich daraufhin einleitete, lieferten folgende Ergebnisse:

1. In der einschlägigen Literatur findet man, daß gewisse Völker die Stärke des Farnkrautes als Nahrung gebrauchten.

2. Im Witosch-Gebirge, wo der Adlerfarn in großen Mengen gedeibt, ließen sich aus $1 \mathrm{qm}$ Boden $18 \mathrm{~kg}$ rohe, ungewaschene Rhizome ausgraben, welche nach Abwaschen der anhaftenden Erde ibr Gewicht um $1,4 \mathrm{~kg}$ verminderten. Die gereinigten Rhizome wurden in der Trockenanlage einer Möbelfabrik getrocknet. Nach 4-stündigem Trocknen erhielt man $11 \mathrm{~kg}$ trockene Rhizome.

3. Die trockenen Rhizome wurden z w i mal mit einem gewöhnlichen MühIstein gemahlen und ergaben nach dem Durchsieben $7,6 \mathrm{~kg}$ Mehl. Das gewonnene Mehl war von grauer Farbe, bitterem Geschmack und bildete, mit Wasser angerührt, eine klebrige Masse. 
4. Es wurde aus Weizenmehl mit 25,50 und $75 \%$ von diesem Rhizommehl Teig angemacht und Brot gebacken.

Die Brote mit 50 und $75 \%$ Rhizommebl waren klitschig. Die Brote aus $25 \%$ Rhizommehl und $75 \%$ Weizenmehl, bezw. $50 \%$ Weizen- und $25 \%$ Maismehl waren gut aufgegangen und ließen sich gut ausbacken.

Das Brot hatte einen bitteren Beigeschmack und war durchwegs dunkelbraun gefärbt.

Die Bitterkeit läßt sich durch Auswaschen und Sedimentieren des Mehles beseitigen.

5. Die Analyse des Rhizommehles, welche im Staatlichen Chemischen Institute durchgeführt wurde, lieferte folgende Ergebnisse:

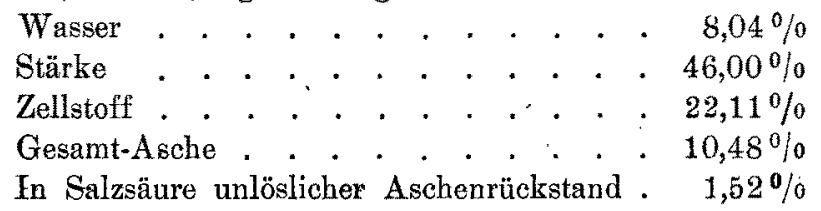

Ein Teil derselben Mehlprobe wurde im Staatlichen Bakteriologischen Institut einer toxikologischen Untersuchung unterzogen; es zeigte sich, daß das Mehl sowohl bei der Verabreichung per os, als auch bei subkutanen Injektionen eines Wasserextraktes unschädlich war.

Die Untersuchung führte also zu folgenden Ergebnissen:

Das in der beschriebenen Art gewonnene Rhizommehl ist, da es reich an Zellstoff, Asche und bitteren Substanzen (Philicin?, Philicinsäure? und ätherischen Ölen?) ist, welche wahrscheinlich in der Rinde der Rhizome angehäuft sind, nicht als Mehl für Backzwecke geeignet, es stellt aber ein wertvolles Futtermittel dar.

In Anbetracht der weiten Verbreitung des Adlerfarnes können die Winterrhizome dieser Pflanze gut ausgebeutet werden, nur muB man mit dem Sammeln schon im frühen Frühling anfangen, solange der Stärkevorrat durch die Vegetation nicht zu sehr angegriffen ist. Das Ausgraben erfolgt leicht durch kleine Raketenexplosioneh.

Das Trocknen der Rhizome kann in Ziegel-, Bretter- oder Gemüse-Trockenanlagen geschehen.

\title{
Die Säure der Weine des Jahrgangs 1917.
}

\author{
Von \\ Dr. Friedrich Tretzel.
}

Mitteilung aus der Kgl. Untexsuchungsanstaltzu Würzburg.

[Eingegangen am 21. Mös: 1918.]

Die Sonne hat im Jahre 1917 die Trauben gut zur Ausreife gebracht und eine reichliche Ernte beschieden. Der Most war zuckerreich und im Verhältnis zu früheren Jahrgängen ärmer an Säure; mitunter fanden sich sogar Moste mit sebr niedriger Säure vor, wenn auch so enorm niedrige Zahlen wie im Jahre 1895 nicht beobachtet werden konnten. Es war deshalb von erhöhtem Interesse, zu verfolgen, wie sich der Most ausbaut, in welchem Maße ein Rückgang der Säure stattfindet. 